Ani oni c Li vi ng Pol yreri zat i on of Macr ononomer s: Prepar at i on of a Part i cl e- l i ke Pur gi ng Reagent and Char acteri zat i on of Pol y ( nacr omonomer) s

\begin{tabular}{|l|l|}
\hline 著者 & $\begin{array}{l}\text { SE Kazunor i, I NOUE Nor i hi r o, YANASH TA } \\
\text { Nasanor i }\end{array}$ \\
\hline $\begin{array}{l}\text { j our nal or } \\
\text { publ i cat i on t i t l e }\end{array}$ & Pol ymer \\
\hline vol une & 46 \\
\hline nunber & 23 \\
\hline page $\mathrm{r}$ ange & $9753-9761$ \\
\hline year & $2005-11$ \\
\hline URL & ht t p: //hdl . handl e. net /10098/1397 \\
\hline
\end{tabular}


August 8, 2005

\title{
Anionic Living Polymerization of Macromonomers: \\ Preparation of a Particle-like Purging Reagent and \\ Characterization of Poly(macromonomer)s
}

\author{
Kazunori Se*, Norihiro Inoue and Masanori Yamashita \\ Department of Materials Science and Engineering, Faculty of Engineering, \\ Fukui University, Bunkyo 3-9-1, Fukui 910-8507, Japan
}

* Corresponding author. Tel: +81-776-27-8957; Fax: +81-776-27-8767

E-mail address: se@matse.fukui-u.ac.jp. 


\section{Abstract}

A cross-linked polystyrene particle (Merrifield resin, $\mathrm{R}-\mathrm{C}_{6} \mathrm{H}_{5}$ ) was reacted with benzoyl chloride in nitrobenzene to produce $\mathrm{R}-\mathrm{C}_{6} \mathrm{H}_{4}-\mathrm{COC}_{6} \mathrm{H}_{5}$ having a benzophenone group, and the $\mathrm{R}-\mathrm{C}_{6} \mathrm{H}_{5}-\mathrm{COC}_{6} \mathrm{H}_{5}$ was reacted with a sodium mirror in THF under $10^{-5} \mathrm{mmHg}$ to produce $\mathrm{R}-\mathrm{C}_{6} \mathrm{H}_{5}-\mathrm{CO}_{6} \mathrm{C}_{6} \mathrm{H}_{5} \mathrm{Na}^{+}$containing a benzophenone sodium as a particle-like purging reagent (PPBNa). (4-Vinylbenzyl)polystyrene macromonomers (PSM4: $M_{\mathrm{n}}=4.6_{2} \times 10^{3}$, $M_{\mathrm{w}} / M_{\mathrm{n}}=1.0_{3}$ and PSM7: $\left.M_{\mathrm{n}}=7.1_{0} \times 10^{3}, M_{\mathrm{w}} / M_{\mathrm{n}}=1.0_{2}\right)$ were dried under $10^{-6} \mathrm{mmHg}$ for more than $72 \mathrm{~h}$, purified by a special procedure using the PPBNa, and then were living anionically polymerized by $s e c$-BuLi in benzene or $n$-BuLi in tetrahydrofuran to produce the corresponding poly $(\mathrm{PSM})_{\mathrm{n}}$ star polymers. The resultant star polymers were characterized by gel permeation chromatography equipped with low-angle laser light-scattering (GPC-LALLS), membrane osmometry (OSM), and light-scattering (LS). Anionic living polymerization of the PSM macromonomers was confirmed by the fact that the molecular weight of the poly(PSM $)_{n}$ increased and by the fact that the initiation efficiency was constant despite an increase in the polymer yields. Some solution properties and specific dimensions characteristic to the poly(PSM) $)_{\mathrm{n}}$ star polymers are discussed by comparing the GPC-LALLS, OSM, and LS results for those polymers with the results for linear polystyrenes.

Keywords: anionic living polymerization / macromonomers / a cross-linked polystyrene particle having a benzophenone-sodium / star polymers / a particle-like purging reagent / initiation efficiency 


\section{Introduction}

Because of their asymmetric shapes, non-linear block copolymers, such as mikto-arm star block copolymers [1], block-graft copolymers [2, 3], and rod-coil block copolymers [4], have shown some unique physical properties [5], such as liquid crystallinity [6], anisotropic solution, and dielectric [7] and rheological behaviors [8]. To prepare these non-linear block copolymers, synthetic routes might be sophisticated and the final products would be small in quantity. Simpler, more general synthetic routes than those reported thus far are needed in order to prepare non-linear block copolymers in sufficient quantities.

Anionic living polymerization of macromonomers [9-16] is one of the synthetic routes expected to be useful for preparing non-linear block copolymers. Purification of macromonomers is one of the major problems encountered in their anionic living polymerization [17]. In the purification of common monomers such as styrene, the monomers are distilled from mixtures containing them and organometallic compounds, the latter serving as purging reagents in a sealed glass apparatus at $10^{-5} \mathrm{mmHg}$. However, because macromonomers cannot be distilled even in a high vacuum, a new method for purifying them is needed.

Before preparing non-linear block copolymers, the present paper describes the synthesis of a particle-like purging reagent, that can purify macromonomers by a new technique, and describes the anionic living polymerization of (4-vinylbenzyl)polystyrene macromonomers (PSM), which were purified by the particle-like purging reagent to prepare star polymers. Initiation efficiency is one of the most important characteristics in discussing the livingness of the polymerization [18]. In order to discuss the livingness, the resultant star polymers are characterized in detail to determine their molecular weights by a special analysis using gel permeation chromatography equipped with low-angle laser 
light-scattering (GPC-LALLS) [19], membrane osmometry, and light-scattering. The initiation efficiency of the anionic living polymerization of PSM was determined by comparing the accurately determined molecular weights with the kinetic molecular weights calculated from the amounts of PSM and initiators.

Preliminary solution properties of the resultant poly $(\mathrm{PSM})_{\mathrm{n}}$ star polymers are discussed on the basis of the results of membrane osmometry and light-scattering. On the other hand, the structure characteristics of the poly(PSM) $)_{\mathrm{n}}$ are also discussed on the basis of the results of the GPC-LALLS measurements; namely, the relationship between the molecular weights and molecular dimensions of the poly $(\mathrm{PSM})_{\mathrm{n}}$ in solution can be derived by a conventional GPC-LALLS experiment, its special analysis, and a common theory for comb-like chains.

\section{Experimental}

\section{1. Reagents}

sec-Butyllithium (sec-BuLi) and normal-butyllithium (n-BuLi) were purchased and diluted with purified $n$-heptane. The concentrations of the initiators were determined by titration with a standard $\mathrm{HCl}$ solution. Styrene $(\mathrm{St})$ was dried over calcium hydride under $10^{-5} \mathrm{mmHg}$ and purified with octylbenzophenone sodium [20]. (4-Vinylbenzyl)chloride (4VBC) was prepared through a common method [21] previously used by the present authors

[20]. The resultant $4 \mathrm{VBC}$ was dried over calcium hydride several times under $10^{-5} \mathrm{mmHg}$.

Toluene and benzene used for polymerization and $n$-heptane used for dilution of the initiators were dried with sodium metal, distilled in a vacuum with the sodium metal, and then purified by distillation from a mixture of diphenylhexyllithium. Tetrahydrofuran 
(THF) used for polymerization was dried with sodium metal, distilled in a vacuum with anthracene sodium, and then purified by distillation from a mixture of $\alpha$-methyl styrene tetramer sodium.

\section{2. Macromonomers}

St was anionically polymerized by sec-BuLi in toluene at room temperature under $10^{-5}$ mmHg. Then, the polymerization solution was kept at $-78^{\circ} \mathrm{C}$ and was changed to a mixture of toluene/THF (1/1 v/v) by adding THF. Then, THF solution of 4VBC $([4 \mathrm{VBC}] /[\mathrm{sec}-\mathrm{BuLi}]=14)$ was added to the polymerization solution at $-78^{\circ} \mathrm{C}$ to prepare the (4-vinylbenzyl)polystyrene macromonomer (PSM) [21, 22].

Coupling efficiency $\left(f_{\mathrm{c}}\right)$ was determined by the following two methods: (1) $M_{\mathrm{n}}^{\mathrm{NMR}}$ was determined from a ratio of relative ${ }^{1} \mathrm{H}$ NMR intensities of polystyrene to a $\mathrm{CH}_{2}=\mathrm{C}$ group (5.7 ppm and $6.7 \mathrm{ppm}$ ) introduced into a chain end, and $M_{\mathrm{n}}$ was determined by gel permeation chromatography (GPC) and/or vapor pressure osmometry (Hitachi 117 type). The $f_{\mathrm{c}}$ value was determined by $M_{\mathrm{n}} / M_{\mathrm{n}}^{\mathrm{NMR}}$. $\quad$ (2) The $f_{\mathrm{c}}$ value was also determined by the comparison of relative ${ }^{1} \mathrm{H}$ NMR intensities between the two $\mathrm{CH}_{3}$ groups $(0.55-0.80 \mathrm{ppm})$ of sec-butyl group at a chain end and a $\mathrm{CH}_{2}=\mathrm{C}$ group introduced at another chain end [22]. The two $f_{\mathrm{c}}$ values coincide with each other with an error of less than $1 \%$. Molecular characteristics and the $f_{\mathrm{c}}$ values of PSM macromonomers are described in $\underline{\text { Table } \mathbf{1}}$.

The PSM macromonomers were dissolved in THF and precipitated in excess methanol to remove the $4 \mathrm{VBC}$, which was not reacted with polystyryllithium. The Bz solution of the resultant PSM was introduced to an ampoule with a break seal, freeze-dried under vacuum for $10 \mathrm{~h}$, and sealed off by flame. The freeze-dried PSM was further dried under $10^{-6} \mathrm{mmHg}$ for $72 \mathrm{~h}$ and sealed off by flame. The dried PSM was purified in a sealed glass apparatus by a 
special procedure using a particle-like purging reagent. The procedure is described in detail in the next section.

\section{3. A purging reagent}

A cross-linked polystyrene particle containing divinylbenzene (1 wt $\%)$ (Merrifield resin, $\mathrm{R}-\mathrm{C}_{6} \mathrm{H}_{5}$, PP) was purchased from Peptide Institute, Inc [23]. For a representative synthetic example, the $\mathrm{R}-\mathrm{C}_{6} \mathrm{H}_{5}$ particle $(30 \mathrm{~g}, 0.29 \mathrm{~mol})$ was reacted with benzoyl chloride $\left(\mathrm{C}_{6} \mathrm{H}_{5} \mathrm{COCl}, 41 \mathrm{~g}, 0.29 \mathrm{~mol}\right)$ in nitrobenzene $(150 \mathrm{ml})$ using aluminum chloride $\left(\mathrm{AlCl}_{3}, 60 \mathrm{~g}\right.$, $0.45 \mathrm{~mol})$ at $30^{\circ} \mathrm{C}$ under dry nitrogen for $2 \mathrm{~h}$ to produce $\mathrm{R}-\mathrm{C}_{6} \mathrm{H}_{4}-\mathrm{COC}_{6} \mathrm{H}_{5}(\mathrm{PPB})$ having a benzophenone group as a side chain. The PPB particle was washed with methanol and dried under $10^{-5} \mathrm{mmHg}$ for $48 \mathrm{~h}$. Subsequent metallation of PPB was carried out at $10^{-5}$ $\mathrm{mmHg}$ in an all-glass apparatus equipped with break seals. The PPB particle $(25 \mathrm{~g})$ was reacted with a sodium mirror in THF $(250 \mathrm{ml})$ at room temperature for 15 days under $10^{-5}$ $\mathrm{mmHg}$ to produce a cross-linked polystyrene particle having a benzophenone sodium complex $\left(\mathrm{R}-\mathrm{C}_{6} \mathrm{H}_{5}-\mathrm{CO}^{-} \mathrm{C}_{6} \mathrm{H}_{5} \mathrm{Na}^{+}\right.$, PPBNa). This particle is called a particle-like purging reagent.

\section{4. Polymerization}

PSM macromonomers and poly(PSM $)_{n}$ star polymers were prepared using an anionic living polymerization technique. Polymerization was carried out in a sealed glass apparatus under a pressure of $10^{-5} \mathrm{mmHg}$. The polymerization techniques were almost the same as those employed in previous studies conducted by the present authors [20].

\section{5. Molecular characterization}


The number average molecular weights $\left(M_{\mathrm{n}}\right)$ of PSM macromonomers were determined by vapor pressure osmometry (VPO; Model 117, Hitachi, Tokyo, Japan) in Bz at $30^{\circ} \mathrm{C}$ and by GPC (Model CCPD, Tosoh Co., Tokyo, Japan). Molecular characterization of all the samples was carried out in THF using GPC equipped with a low-angle laser light-scattering (GPC-LALLS) detector (Model LS-8000, Tosoh Co., Tokyo, Japan) and RI detector (RI-8010, Tosoh Co., Tokyo, Japan). Two high-resolution columns $(7.8 \mathrm{~mm}$ x $60 \mathrm{~cm}$; Tosoh Co., Tokyo, Japan) were connected in series with the GPC measurements.

When characterizing star polymers by a common GPC technique, number average molecular weights $\left(M_{\mathrm{n}}\right)$ and weight average molecular weights $\left(M_{\mathrm{w}}\right)$ cannot be determined by a conventional analysis [19]. One has to obtain two GPC chromatograms: the refractive index $(\mathrm{RI})$ intensity $\left(H_{i}^{\mathrm{RI}}\right)$ and the LALLS intensity $\left(H_{i}^{\mathrm{LS}}\right)$ of the corresponding $\mathrm{RI}$ and LALLS chromatograms of the star polymers at the $i$-th elution volume. These two intensities are described as follows.

$$
\begin{aligned}
& H_{i}^{\mathrm{RI}}=k_{\mathrm{RI}}(d n / d c)_{i} C_{i} \\
& H_{i}^{\mathrm{LS}}=k_{\mathrm{LS}}\left[(d n / d c)_{i}\right]^{2} M_{i} C_{i}
\end{aligned}
$$

Where $M_{i},(d n / d c)_{i}$, and $C_{i}$ are the molecular weight, RI increment, and concentration of the star polymers at the $i$-th elution volume, respectively. The $k_{\mathrm{RI}}$ and $k_{\mathrm{LS}}$ are instrumental constants of the RI and LALLS detectors, respectively, and are determined using standard polystyrene. Therefore, $M_{i}$ in eq. (2) can be shown as follows:

$$
\left.M_{i}=\left[\left(k_{\mathrm{RI}}\right)^{2} / k_{\mathrm{LS}}\right]\right]\left[\left(H_{i}^{\mathrm{LS}} /\left(H_{i}^{\mathrm{RI}}\right)^{2}\right) C_{i}\right.
$$


By substituting $M_{i}$ in $M_{\mathrm{n}}=\Sigma H_{i}^{\mathrm{RI}} / \Sigma\left(H_{i}^{\mathrm{RI}} / M_{i}\right)$ and $M_{\mathrm{w}}=\Sigma H_{i}^{\mathrm{RI}} M_{i} / \sum H_{i}^{\mathrm{RI}}$, the corresponding $M_{\mathrm{n}}$ and $M_{\mathrm{w}}$ were calculated.

The $M_{\mathrm{n}}^{\text {OSM }}$ was also determined by osmometry in toluene at $30^{\circ} \mathrm{C}$ using a high-speed membrane osmometer (Mechrolab Model 502, Hewlett-Packard Co., California, US) and the $M_{\mathrm{w}}{ }^{\mathrm{LS}}$ was determined by light scattering in benzene at $30^{\circ} \mathrm{C}$ using a light-scattering instrument (DLS-7000, Otsuka Electronics Co., Tokyo, Japan).

\section{Results and discussion}

\section{1. Synthesis of a particle-like purging reagent}

The synthetic route to synthesize a particle-like purging reagent is as follows. A cross-linked polystyrene particle (Merrifield resin, $\mathrm{R}-\mathrm{C}_{6} \mathrm{H}_{5}, \mathrm{PP}$ ) is not soluble in solvents, so it was sedimented in suspension without stirring. The $\mathrm{R}-\mathrm{C}_{6} \mathrm{H}_{5}$ particle was reacted with benzoyl chloride $\left(\mathrm{C}_{6} \mathrm{H}_{5} \mathrm{COCl}\right)$ in nitrobenzene using aluminum chloride $\left(\mathrm{AlCl}_{3}\right)$ under dry nitrogen to produce $\mathrm{R}-\mathrm{C}_{6} \mathrm{H}_{4}-\mathrm{COC}_{6} \mathrm{H}_{5}(\mathrm{PPB})$ having a benzophenone group as a side chain.

$$
\mathrm{R}-\mathrm{C}_{6} \mathrm{H}_{5}+\mathrm{C}_{6} \mathrm{H}_{5} \mathrm{COCl} \longrightarrow \quad \mathrm{R}-\mathrm{C}_{6} \mathrm{H}_{5}-\mathrm{COC}_{6} \mathrm{H}_{5}(\mathrm{PPB})
$$

The experimental conditions and results of eq. (4) are described in Table 2 . The degree of PPB conversion was determined by gravimetric analysis. Even if the reaction temperature is high, reaction time long (No. 1 and No. 2 in Table 2), and the ratio of $\left[\mathrm{AlCl}_{3}\right] /\left[\mathrm{C}_{6} \mathrm{H}_{5} \mathrm{COCl}\right]$ high (No. 2), the conversions per styrene unit of eq. (4) did not reach $100 \%$ and are probably all the same values (67\%). The resultant product of No. 1 was a 
dark brown due to adsorption of some by-products of $\mathrm{AlCl}_{3}$. However, the final product of No. 3 was light yellow due to the introduction of the benzophenone group.

The PPB particle suspended in THF was reacted with a sodium mirror in THF at room temperature under $10^{-5} \mathrm{mmHg}$ to produce a polystyrene particle having a benzophenone sodium complex $\left(\mathrm{R}-\mathrm{C}_{6} \mathrm{H}_{5}-\mathrm{CO}_{6}^{-} \mathrm{C}_{5} \mathrm{H}_{5} \mathrm{Na}^{+}, \mathrm{PPBNa}\right)$. This particle is called a particle-like purging reagent.

$$
\mathrm{R}-\mathrm{C}_{6} \mathrm{H}_{5}-\mathrm{COC}_{6} \mathrm{H}_{5}+\mathrm{Na} \longrightarrow \mathrm{R}-\mathrm{C}_{6} \mathrm{H}_{5}-\mathrm{CO}^{-} \mathrm{C}_{6} \mathrm{H}_{5} \mathrm{Na}^{+}(\mathrm{PPBNa})
$$

The PPBNa prepared from particle No. 1 in Table 2 changed from dark brown to green for $1 \mathrm{~h}$, to dark green for 1 day, and to dark blue for 2 days in the process of reaction with the sodium mirror. The PPBNa prepared from particle No. 3 in Table 2 changed from light yellow to green for $1 \mathrm{~h}$, to blue for 2 hour, to dark blue for 2 days, and to purple for 4 days. When the PPBNa suspended in THF was under atmosphere, it changed to dark brown (No. 1) and to light yellow (No. 3) after a minute in atmosphere. When water was introduced to the PPBNa suspended in THF, the mixture produced sodium hydroxide, and the resultant mixture was titrated with $\mathrm{HCl}$ solution. From the neutralization analysis, the metallation efficiency per unit of $\mathrm{R}-\mathrm{C}_{6} \mathrm{H}_{5}-\mathrm{COC}_{6} \mathrm{H}_{5}$ was determined. As shown in Figure 1, the metallation efficiency increases with an increase in the reaction time of PPB with the sodium mirror and reached $100 \%$ for 15 days for the particle No. 3 in Table $2 . \quad$ In contrast, the metallation efficiency of the particle No. 1 was low even after 13 days due to the adsorption of some by-products of $\mathrm{AlCl}_{3}$. In comparison with the solution reaction, the present reaction takes a long time because of the suspension reaction. In conclusion, PPBNa as a particle-like 
purging reagent was prepared from particle No. 3 and its metallation efficiency per unit of PPB was $100 \%$.

The PPBNa was found to have a sodium content of $8.1 \mathrm{wt} \%$. When purifying St, octylbenzophenone sodium $\left(\mathrm{C}_{8} \mathrm{H}_{17}-\mathrm{C}_{6} \mathrm{H}_{4}-\mathrm{CO}^{-}-\mathrm{C}_{6} \mathrm{H}_{5} \mathrm{Na}^{+}\right)$having a sodium content of $7.3 \mathrm{wt} \%$ is used as a purging reagent. The sodium content of PPBNa seems to be the same as that of octylbenzophenone sodium. In contrast, octylbenzophenone sodium is soluble in styrene. However, PPBNa was suspended in, rather than soluble in the THF or Bz solution of PSM macromonomers. Therefore, PPBNa would not work as a high-performance purging reagent such as octylbenzophenone sodium, but could be employed as a purging reagent for the macromonomers even if the purification takes a long time.

\section{2. Estimation of a particle-like purging reagent}

To estimate PPBNa's effectiveness as a particle-like purging reagent, preliminary polymerizations of St were performed. St was dried over calcium hydride $\left(\mathrm{CaH}_{2}\right)$ under $10^{-5}$ $\mathrm{mmHg}$ and was not subsequently purified with octylbenzophenone sodium. The resultant St was anionically polymerized by a common polymerization technique, and the initiation efficiency $\left(f_{\mathrm{I}}\right)$ was determined from $M_{\mathrm{k}} / M_{\mathrm{n}}$ of the resultant polystyrene, where $M_{\mathrm{k}}$ is a kinetic molecular weight calculated from amounts of St and initiator. As shown in Table $\mathbf{3}$, the $f_{\mathrm{I}}$ value was 0.90 . Hence, the St used in the present polymerization was found to contain small amounts of impurities, that decrease the $f_{\mathrm{c}}$ value.

In contrast, the St dried over calcium hydride was subsequently purified using the same purification technique used for the macromonomers. As shown in Figure 2, the inside of the glass apparatus was washed with THF solution of diphenylhexyllithium, and the THF solution was collected in the ampoule (a) and then sealed off by flame. The PPBNa 
suspended in THF was introduced into a glass reactor (b), the THF was distilled in an ampoule (c) kept in liquid nitrogen, and the ampoule was sealed off by flame. Then, the St dried over calcium hydride was introduced into the reactor (b) and the suspended mixture was stirred at room temperature for $3 \mathrm{~h}$. The St was then separated from the suspension by a glass filter (d) and was introduced into an ampoule (e). A part of the resultant St was checked to see whether or not the St had become polystyrene during purification. No polystyrene was prepared. The resultant St was anionically polymerized, and the initiation

efficiency $\left(f_{\mathrm{I}}\right)$ was determined. As shown in Table 3, the $f_{\mathrm{I}}$ value was 1.00 . The PPBNa was found to work as a purging reagent for the monomers employed in the anionic living polymerization.

\section{3. Anionic polymerization of PSM macromonomers}

Three PSM macromonomers were dried under $10^{-5} \mathrm{mmHg}$ for more than $72 \mathrm{~h}$ and purified by the new technique using PPBNa as a particle-like purging reagent as described in a previous section. The purified PSMs were anionically polymerized in two polymerization conditions. One is the non polar solvent system of $s$-BuLi/Bz/room temperature as the initiator/solvent/polymerization temperature, and another is the polar solvent system of n-BuLi/THF $/-78^{\circ} \mathrm{C} . \quad$ The polymerization conditions are shown in Table 4.

When the initiators were introduced into the solutions of PSM, the polymerization solutions changed for a few seconds from colorless to red, a characteristic color of carbanions. The solutions maintained a red color during polymerization and changed to colorless at the moment when methanol was introduced into the solutions. These facts correspond to the livingness of the poly(PSM $)_{n}$ carbanions. On the other hand, in the case of the poly(PSM7) $)_{n} / \mathrm{Bz}$ system, the polymerization solution changed to red for a few second after 
the introduction of an initiator, gradually changed to light red for a minute, and then changed to colorless for 10 minutes after the ampoules of the precursors were sealed off by flame. These facts correspond to the deactivation of the poly(PSM $)_{n}$ carbanions in the polymerization process.

As shown in Figure 3, a GPC peak of poly(PSM4) 4.89 $_{\text {appears at higher molecular }}$ weight sides than that of the PSM4 macromonomer. As the polymerization time increased, the GPC peaks of poly(PSM4) $)_{n}$ shifted to higher molecular weight sides and their peak strength increased. Simultaneously, the GPC peak strengths of PSM4 decreased as polymerization time increased.

The $M_{\mathrm{n}}$ and $M_{\mathrm{w}}$ values of the poly(PSM) $)_{\mathrm{n}}$ star polymers were determined by GPC-LALLS. As shown in Figure 4, the $M_{\mathrm{n}}$ value of poly(PSM4) in a poly(PSM4) $/ \mathrm{Bz}$ system increases linearly with an increase in the polymer yield. The $M_{\mathrm{w}} / M_{\mathrm{n}}$ values are 1.1 . These behaviors suggest the livingness of the PSM4 macromonomer polymerization. In the case of the poly(PSM4) $)_{n} /$ THF system, it was experimentally difficult to obtain poly(PSM4) as precursors by flame in the process of polymerization because of the low polymerization temperature $\left(-78^{\circ} \mathrm{C}\right)$ and the high polymerization rates. Hence, the polymerization results have to appear in high polymer yield sides. On the other hand, PSM7 in the poly(PSM7) $)_{n} / \mathrm{Bz}$ system was polymerized in a polymer yield of less than $30 \%$. The deactivation of the living Poly(PSM7) $)_{\mathrm{n}}$ carbanions occurred during polymerization.

The initiation efficiency $\left(f_{\mathrm{I}}\right)$ is one of the most important characteristics when discussing living polymerization [18]. Before we discuss living polymerization, attention should be directed to the relationship between livingness and the $f_{\mathrm{I}}$ value. Livingness should keep the $f_{\mathrm{I}}$ value to 1.0 in a polymer yield of $0-100 \%$. However, even if the polymerization is performed by a living mechanism, it is common for the $f_{\mathrm{I}}$ value to be less 
than 1.0 , because (1) some of the initiators were deactivated by impurities contained in the polymerization solution at an initial stage of polymerization, or (2) some of the initiators were deactivated by the glass surface of the ampoule when the initiators were kept in a refrigerator for a long time before polymerization. It is important that even if the $f_{\mathrm{I}}$ value is less than 1.0 , livingness should keep the $f_{\mathrm{I}}$ value constant in a polymer yield of $0-100 \%$. In contrast, if the $f_{\mathrm{I}}$ value decreases with an increase in the polymer yield, the living ends were deactivated in the process of polymerization. That is, the polymerization mechanism cannot be livingness.

As shown in Figure 5, the poly(PSM4) $/$ Bz system shows its $f_{\mathrm{I}}$ values to be 0.87 in a polymer yield of $40 \%-90 \%$. A poly(PSM4) $/$ THF system shows its $f_{\mathrm{I}}$ values to be 0.98 in a polymer yield of $100 \%$. The polymer yield dependence of these two $f_{\mathrm{I}}$ values indicates that the anionic living mechanism of PSM macromonomers proceeds in the present polymerization system. In contrast, the poly(PSM7) $/ \mathrm{Bz}$ system shows its $f_{\mathrm{I}}$ values to be 0.55 in a polymer yield of $30 \%$. Some of the initiators were deactivated by impurities contained in the polymerization solution, and the residual initiator polymerized PSM. So, the $f_{\mathrm{I}}$ value $(0.55)$ became less than 1.0 , because PSM7 was purified with PPBNa in Bz as a non polar solvent and for a short purging time $(3 \mathrm{~h})$ rather than the longer purging time $(12 \mathrm{~h})$ of the other two systems. In addition, when the ampoules of precursors were sealed off by flame, small amounts of polymers might be decomposed to produce impurities. The poly(PSM7) $)_{n}$ carbanions could have been deactivated by these additional impurities. This speculation corresponds to the fact that the polymerization solution of poly(PSM7) $)_{\mathrm{n}}$ changed from light red to colorless after the ampoules of the precursors were sealed off by flame. In conclusion, anionic living polymerization of the PSM macromonomers was confirmed by the fact that $M_{\mathrm{n}}$ of poly $(\mathrm{PSM})_{\mathrm{n}}$ increased and by the fact that $f_{\mathrm{I}}$ was constant despite the increase 
of the polymer yields when the PSM was sufficiently purified with PPBNa as a purging reagent.

\section{4. Molecular characteristics of poly $(P S M)_{n}$ star polymers}

The $M_{\mathrm{n}}^{\text {LALLS }}$ and $M_{\mathrm{w}}^{\text {LALLS }}$ of the poly(PSM) $)_{\mathrm{n}}$ star polymers were determined by GPC-LALLS [18]. The validity of determining the $M_{\mathrm{n}}^{\text {LALLS }}$ and $M_{\mathrm{w}}^{\text {LALLS }}$ by GPC-LALLS was demonstrated by experiments in membrane osmometry and light-scattering, and some solution properties of poly $(\mathrm{PSM})_{\mathrm{n}}$ star polymers were estimated. Figure 6 shows the concentration dependence of osmotic pressure for poly(PSM4) ${ }_{10.1}$ prepared by $n$-BuLi in THF at $-78{ }^{\circ} \mathrm{C}$. The $M_{\mathrm{n}}^{\text {OSM }}$ was determined from an intercept, and a second virial coefficient, $A_{2}{ }^{\text {OSM }}$, was determined from the slope of a linear line. On the other hand, Figure 7 shows a Zimm plot of a light-scattering measurement of poly(PSM4) ${ }_{10.1}$. The $M_{\mathrm{w}}{ }^{\mathrm{LS}}, A_{2}^{\mathrm{LS}}$, and radius of gyration $\left.\left(<S^{2}\right\rangle^{1 / 2}\right)$ were determined by a common analysis.

As shown in Table 5, $M_{\mathrm{n}}^{\text {OSM }}\left(4.6_{1} \times 10^{4} \mathrm{~g} \mathrm{~mol}^{-1}\right)=M_{\mathrm{n}}^{\text {LALLS }}\left(4.6_{5} \times 10^{4} \mathrm{~g} \mathrm{~mol}^{-1}\right)$ with an error of $1.0 \%$, and $M_{\mathrm{w}}{ }^{\mathrm{LS}}\left(5.0_{4} \times 10^{4} \mathrm{~g} \mathrm{~mol}^{-1}\right)=M_{\mathrm{w}}{ }^{\mathrm{LALLS}}\left(4.9_{5} \times 10^{4} \mathrm{~g} \mathrm{~mol}^{-1}\right)$ with an error of 1.8\%. The special analysis using GPC-LALLS [19] was found to be applicable for determining $M_{\mathrm{n}}$ and $M_{\mathrm{w}}$.

The $A_{2}{ }^{\text {OSM }}$ value $\left(2.8_{7} \times 10^{-4} \mathrm{~cm}^{3} \mathrm{~g}^{-2} \mathrm{~mol}\right)$ is not equal to the $A_{2}^{\mathrm{LS}}$ value $\left(3.8_{3} \times 10^{-4} \mathrm{~cm}^{3}\right.$ $\mathrm{g}^{-2}$ mol). This discrepancy between $A_{2}{ }^{\text {OSM }}$ and $A_{2}{ }^{\mathrm{LS}}$ had been reported several times. The $A_{2}^{\mathrm{LS}}$ value should be the correct one, because the photoconductor used in the light-scattering measurement is capable of greater precision than can be attained by a classical form of measurement such as osmometry. The $A_{2}^{\mathrm{LS}}$ value $\left(3.8_{3} \times 10^{-4} \mathrm{~cm}^{3} \mathrm{~g}^{-2} \mathrm{~mol}\right)$ of poly(PSM4) ${ }_{10.1}$ became smaller than that of the linear PSt $\left(6.5 \times 10^{-4} \mathrm{~cm}^{3} \mathrm{~g}^{-2} \mathrm{~mol}\right)[24,25]$ having the same $M_{\mathrm{n}}$ as that of poly(PSM4) $)_{10.1}$. The $\left\langle S^{2}>^{1 / 2} \text { value of poly(PSM4) }\right)_{10.1}$ was $6.4_{5} \mathrm{~nm}$, which is 
smaller than that of the linear PSt $(7.9 \mathrm{~nm})[26,27]$ having the same $M_{\mathrm{n}}$ as that of poly(PSM4) $)_{10.1}$. These facts correspond to the structural difference between star and linear polymers in good solvents.

From a dynamic light-scattering measurement, a diffusion constant $\left(D_{0}^{\text {star }}=6.3_{5} \times 10^{-7}\right.$ $\left.\mathrm{cm}^{2} \mathrm{~s}^{-1}\right)$ and a hydrodynamic radius $\left(R_{\mathrm{H}}^{\text {star }}=5.7_{0} \mathrm{~nm}\right)$ of poly $(\mathrm{PSM} 4)_{10.1}$ were also determined. Compared with the $D_{\mathrm{o}}^{\text {linear }}$ value $\left(4.9 \times 10^{-7} \mathrm{~cm}^{2} \mathrm{~s}^{-1}\right)$ and the $R_{\mathrm{H}}^{\text {linear }}$ value $(7.4 \mathrm{~nm})$ of a linear PSt having the same $M_{\mathrm{n}}$ as that of poly(PSM4) $)_{10.1}[25,26]$, the following relation was found: $D_{\mathrm{o}}^{\text {star }}$ $>D_{\mathrm{o}}^{\text {linear }}$ and $R_{\mathrm{H}}^{\text {star }}<R_{\mathrm{H}}^{\text {linear }}$. These facts also correspond to the structural difference between star and linear polymers in good solvents [28].

\section{5. The specific dimensions of the poly $(P S M)_{n}$ star polymers}

Attention should be directed to the molecular structure or a specific dimension of the poly $(\mathrm{PSM})_{\mathrm{n}}$ star polymers in THF. For this purpose, light-scattering measurements must be performed to determine the relationship between $M_{\mathrm{w}}$ and $\left\langle S^{2}>\right.$ of $\operatorname{poly}(\mathrm{PSM})_{\mathrm{n}}$ star polymers. A preliminary experiment has been carried out for poly(PSM4) ${ }_{10.1}$. Though the detailed study will be carried out in the future, a brief discussion of a specific dimension of $\operatorname{poly}(\mathrm{PSM})_{\mathrm{n}}$ in THF follows.

The polystyrene-reduced molecular weights $\left(M_{\mathrm{n}}^{\mathrm{GPC}}{ }_{\text {star }}\right)$ of the resultant poly(PSM $)_{\mathrm{n}}$ star polymers were also determined by a common GPC technique using standard polystyrenes. The $M_{\mathrm{n}}{ }_{\text {GPC }}$ star values correspond to the dimensions of the star polymers in THF as a result of the mechanism of the GPC measurements. Hence, the $M_{\mathrm{n}}^{\mathrm{GPC}}{ }_{\text {star }} / M_{\mathrm{n}}{ }_{\text {LALLS }}$ star ratios might correspond to the specific volume $\left(v_{\mathrm{s}}^{\text {star }}\right)$ of the poly(PSM $)_{\mathrm{n}}$ star polymers in THF [29]:

$$
v_{\mathrm{s}}^{\text {star }}=M_{\mathrm{n}}^{\mathrm{GPC}}{ }_{\mathrm{star}} / M_{\mathrm{n}}^{\mathrm{LALLS}} \text { star }
$$


In the case of linear poly(styrene)s (PSt), linear poly(methyl methacrylate)s (PMMA), and linear $\operatorname{poly}\left(n\right.$-hexyl isocyanate)s (PHIC), the $M_{\mathrm{n}}^{\mathrm{GPC}} / M_{\mathrm{n}}^{\text {LALLS }}$ ratios were determined by GPC-LALLS as 1.0, 0.8, and 1.9, respectively [29]. The higher value for the PHIC reflects the bulkiness of the rodlike polymer [30].

The $v_{\mathrm{s}}^{\text {star }}$ values of the poly $(\mathrm{PSM})_{\mathrm{n}}$ star polymers are plotted against the number of arms (n). As compared with the constant $M_{\mathrm{n}}^{\mathrm{GPC}} / M_{\mathrm{n}}^{\text {LALLS }}$ values of linear PSt, PMMA, and PHIC polymers, the $v_{\mathrm{s}}^{\text {star }}$ values decreased with an increase of the number of arms $(n)$ (Figure 8). This behavior reflects the structure of star polymers. In the case of regular comb-shaped homo-polymers at a $\theta$ state, a mean-square radius of gyration $\left\langle S^{2}\right\rangle_{\text {comb }}$ can be derived (for large $\mathrm{m})$ as $[31,32]$

$$
<S^{2}>_{\text {comb }}=\left[+(1-\lambda)^{7 / 3}(3 n-2) / n^{2}\right]\left(m b^{2} / 6\right)
$$

Therefore, for regular comb-shaped and linear polymers with the same $m$ and $b$ at a $\theta$ state,

$$
g_{\text {comb }}=\left\langle S^{2}\right\rangle_{\text {comb }} /\left\langle S^{2}\right\rangle_{\text {linear }}=\left[\lambda+(1-\lambda)^{7 / 3}(3 n-2) / n^{2}\right]
$$

where $m$ and $b$ are a degree of polymerization of the comb chain and a bond length, respectively; $\left\langle S^{2}\right\rangle_{\text {linear }}$ is the mean-square radius of gyration for a linear polymer chain; and $\lambda$ and $n$ are the fraction of mass in the backbone and the number of branches, respectively. The term $(3 n-2) / n^{2}$ is well known to be a $g_{\text {star }}$ value of a regular star polymer. The $g_{\text {comb }}$ value estimated from eq. (8) may be considered a measure of branching.

In the case of poly(PSM4) $)_{\mathrm{n}} \lambda$ can be estimated as $0.023(=104 /(4620-104))$. From eq. (8) for $\lambda=0.023$, the $g_{\text {comb }}$ value became equal to the $g_{\text {star }}$ value with an error of less than $2.5 \%$ 
in a range of $\mathrm{n}=2-12$. Therefore, the $g_{\text {comb }}$ can be converted as follows: $g_{\text {comb }}=g_{\text {star }}=$ $\left\langle S^{2}\right\rangle_{\text {star }} /\left\langle S^{2}\right\rangle_{\text {linear }}=v_{\mathrm{s}}^{\text {star }} / v_{\mathrm{s}}^{\text {linear }}=v_{\mathrm{s}}^{\text {star }}$ due to $v_{\mathrm{s}}^{\text {linear }}=1$, where $v_{\mathrm{s}}^{\text {linear }}$ is a specific volume of the linear PSt. Hence,

$$
v_{\mathrm{s}}^{\mathrm{star}}=(3 n-2) / n^{2}
$$

The $v_{\mathrm{s}}^{\text {star }}$ value can be calculated as a function of $n$. As shown in Figure 8, the observed $v_{\mathrm{s}}^{\text {star }}$ curve can be qualitatively explained by eq. (9). However, there is a gap between the observed and calculated curves. This gap is attributed to the fact that the theoretical $v_{\mathrm{s}}^{\text {star }}$ value can be derived at a $\theta$ state and to the fact that the observed $v_{\mathrm{s}}^{\text {star }}$ value can be determined in a good solvent of THF. To achieve a quantitative fit between the two curves, detailed experiments should be carried out at a $\theta$ state.

\section{Conclusion}

A cross-linked polystyrene particle containing benzophenone sodium ( $\mathrm{R}-\mathrm{C}_{6} \mathrm{H}_{5}-\mathrm{CO}_{6} \mathrm{C}_{5} \mathrm{Na}^{+}$, PPBNa) was prepared as a particle-like purging reagent. PPBNa was confirmed to work as a purging reagent by virtue of its increase of the $f_{\mathrm{I}}$ value from 0.90 to 1.00 for the anionic polymerization of St. The PSM macromonomers were purified by a special procedure using PPBNa under $10^{-5} \mathrm{mmHg}$, and were living anionically polymerized by $s e c-\mathrm{BuLi}$ in $\mathrm{Bz}$ or $n$ - $\mathrm{BuLi}$ in THF to produce the corresponding poly(PSM $)_{\mathrm{n}}$ star polymers. Anionic living polymerization of the PSM macromonomers was confirmed by the fact that $M_{\mathrm{n}}$ of the poly $(\mathrm{PSM})_{\mathrm{n}}$ increased and by the fact that $f_{\mathrm{I}}$ was constant despite the increase of the polymer yields. 
The resultant poly(PSM4) $)_{10.1}$ showed characteristic solution properties $\left(A_{2}^{\text {star }}<A_{2}^{\text {linear }}\right.$, $<S^{2}>^{1 / 2}{ }_{\text {star }}<\left\langle S^{2}\right\rangle^{1 / 2}$ linear, $D_{0}^{\text {star }}>D_{0}^{\text {linear }}$, and $R_{\mathrm{H}}{ }^{\text {star }}<R_{\mathrm{H}}^{\text {linear }}$ ) of star polymers, which are different from those of linear polystyrenes having the same $M_{\mathrm{n}}$ as those of poly(PSM4) $)_{10.1}$. The specific dimension $\left(v_{\mathrm{s}}^{\text {star }}\right)$ of the poly $(\mathrm{PSM})_{\mathrm{n}}$ defined by $M_{\mathrm{n}}^{\mathrm{GPC}}{ }_{\text {star }} / M_{\mathrm{n}}^{\mathrm{LALLS}}$ star decreased with an increase in the number of arms $(n)$. This fact was qualitatively explained by the $g_{\text {star }}$ value. However, to determine the best fit between $v_{\mathrm{s}}^{\text {star }}$ and $g_{\text {star }}$, detailed experiments carried out at a $\theta$ state, such as in cyclohexane at $34.5^{\circ} \mathrm{C}$, are needed . 


\section{References}

[1] Hadjichristidis N. Adv Polym Sci 1999; 142: 71.

[2] Se K, Yamazaki H, Shibamoto T, Takano A, Fujimoto T. Macromolecules 1997: 30; 1570.

[3] Se K, Miyawaki K, Hirahar K, Takano A, Fujimoto T. J Polym Sci, Polym Chem Ed 1998; 36: 3021.

[4] Chen JT, Thomas EL, Ober CK, Mao G -p. Science 1996; 273: 343.

[5] Hamley IW. The physics of block copolymers. Oxford: Oxford Sci Publ; 1998.

[6] Sato T, Teramoto A. Adv Polym Sci 1996; 126: 85.

[7] Hirai T, Fujimura N, Urakawa K, Adachi K, Donkai M, Se K. Polymer 2002; 43: 1133.

[8] Se K, Berry GC. Mol Cryst Liq Cryst 1987; 153: 133.

[9] Ito K. Prog Polym Sci 1998; 23: 581.

[10] Ishizu K, Uchida S. Prog Polym Sci 1999; 24: 1439.

[11] Hadjichristidis N, Pitsikalis M, Iatrou H. Pispas S. Macromol Rapid Commun 2003; 24: 979

[12] Pantazis D, Chalari I, Hadjichristidis N. Macromolecules 2003; 36: 3783.

[13] Knauss DM, Huang T. Macromolecules 2003; 36: 6036.

[14] Liu IC, Tsiang RC. J Polym Sci, Polym Chem Ed 2003; 41: 976.

[15] Se K, Suzuki M, Matsuo T, Umeda T. Ueno M. Kobunshi Ronbunshu (Jap J Polym Sci Technol) 1992; 49: 817.

[16] Se K, Suzuki M. Rept Prog Polym Phys Jpn 1993; 36: 491.

[17] Se K, Matsumura K, Kazama T, Fujimoto T. Polymer J 1997; 29: 434.

[18] Se K, Suzuki M, Kobunshi Ronbunshu (Jap J Polym Sci Technol) 2000; 57: 851. 
[19] Se K, Sakakibara T, Ogawa E. Polymer 2002; 43 : 5447.

[20] Se K. Prog Polym Sci 2003; 28: 583.

[21] Asama R, Takaki M, Hanahara H. Macromolecules 1983; 16: 628.

[22] Senoo K, Endo K. J Polym Sci, Part A Polym Chem 2000; 38: 1241.

[23] Address: 4-1-2 Ina, Minoh-Shi, Osaka 562-8686, Japan. http://www.peptide.co.jp

[24] Miyaki Y, Einaga Y, Fujita H. Macromolecules 1978; 11: 1180.

[25] Hokajo T, Trrao K, Nakamura Y, Norisue T. Polym J 2001; 33: 481.

[26] Amitani K, Terao K, Nakamura Y. Norisue T. Polym J 2005; 37: 324.

[27] Brabdrup J, Immergut EH, editors. Polymer handbook, Third ed. New York: Wiley; 1989.

[28] Huang HM, Liu IC, Tsiang RC. Polymer 2005; 46: 955.

[29] Se K, Aoyama K. Polymer 2004; 45: 79.

[30] Murakami H, Norisue T, Fujita H. Macromolecules 1980; 13: 345.

[31] Casassa EF, Berry GC. J Polym Sci, Part A-2: 1966; 4: 881.

[32] Casassa EF, Berry GC. Polymer solution. In: Allen G, editor. Comprehensive polymer science. New York: Pergamon Press; 1988. p. 71. 
Table. 1 Molecular characteristics of PSM macromonomers.

\begin{tabular}{|l|l|l|l|l|l|l|l|}
\hline PSM & St & $s$-BuLi & {$[T] /[I]^{\mathrm{a}}$} & $10^{-3} M_{\mathrm{k}}^{\mathrm{b}}$ & $10^{-3} M_{\mathrm{n}}^{\mathrm{c}}$ & $M_{\mathrm{w}} / M_{\mathrm{n}}{ }^{\mathrm{c}}$ & $f_{\mathrm{C}}^{\mathrm{d}}$ \\
\hline & $\mathrm{g}$ & $\mathrm{mmol}$ & & & & & \\
\hline PSM4 & $8.8_{7}$ & $1.9_{3}$ & $14_{._{2}}$ & $4.6_{0}$ & $4.6_{2}$ & $1.0_{3}$ & 1.00 \\
\hline PSM7 & $7.6_{7}$ & $1.0_{8}$ & $14_{0}$ & $7.1_{0}$ & $7.1_{0}$ & $1.0_{2}$ & 0.97 \\
\hline
\end{tabular}

a The molar ratio of the deactivator (4VBC) to initiator ( $s$-BuLi).

b Kinetic molecular weights determined from the amounts of St to $s$-BuLi.

c Determined by GPC using standard polystyrenes and VPO.

d Coupling efficiency determined by $M_{\mathrm{n}} / M_{\mathrm{n}}^{\mathrm{NMR}}$. 
Table. 2 Preparation of a polystyrene particle having a benzophenone group $\left(\mathrm{R}-\mathrm{C}_{6} \mathrm{H}_{4}-\mathrm{COC}_{6} \mathrm{H}_{5}, \mathrm{PPB}\right)$.

\begin{tabular}{|l|l|l|l|l|l|l|l|}
\hline Particles & \multicolumn{2}{|l|}{${\mathrm{R}-\mathrm{C}_{6} \mathrm{H}_{5}{ }^{\mathrm{a}}}$} & $\mathrm{C}_{6} \mathrm{H}_{5} \mathrm{COCl}$ & $\begin{array}{l}{\left[\mathrm{AlCl}_{3}\right] /} \\
{\left[\mathrm{C}_{6} \mathrm{H}_{5} \mathrm{COCl}\right]}\end{array}$ & Temperature & Time & Conversion $^{\mathrm{b}}$ \\
\hline No. 1 & $29 \cdot \cdot_{4}$ & $0.28_{3}$ & $0.28_{6}$ & 0.52 & 100 & 5 & $68 ._{1}$ \\
\hline No. 2 & $5.0_{0}$ & 0.048 & 0.048 & $2.3_{3}$ & 100 & 5 & $5 \cdot_{1}$ \\
\hline No. 3 & $30_{\cdot_{0}}$ & $0.28_{8}$ & $0.28_{8}$ & $1.5_{5}$ & 30 & 2 & $67 ._{4}$ \\
\hline
\end{tabular}

a A cross-linked polystyrene particle (Merrifield resin).

b Determined by gravimetric analysis. 
Table. 3 Anionic polymerization of styrene dried over $\mathrm{CaH}_{2}$ or PPBNa.

\begin{tabular}{|l|l|l|l|l|l|l|}
\hline Purging & St & $10^{5} I$ & $10^{-4} M_{\mathrm{k}}$ & $10^{-4} M_{\mathrm{n}}^{\mathrm{b}}$ & $M_{\mathrm{w}} / M_{\mathrm{n}}^{\mathrm{b}}$ & $f_{\mathrm{I}}^{\mathrm{c}}$ \\
\hline & & & & & & \\
\hline $\mathrm{CaH}_{2}{ }^{\mathrm{d}}$ & $6.0_{1}$ & $6.7_{5}$ & $8.9_{0}$ & $9.9_{2}$ & $1.0_{7}$ & $0.89_{7}$ \\
\hline $\mathrm{CaH}_{2}+\mathrm{PPBNa}^{\mathrm{d}}$ & $4.9_{7}$ & $7.1_{3}$ & $6.9_{7}$ & $7.0_{0}$ & $1.0_{2}$ & $0.99_{6}$ \\
\hline
\end{tabular}

a Carried out using $n$-BuLi as an initiator in THF at $-78^{\circ} \mathrm{C}$ under $10^{-5} \mathrm{mmHg}$.

b Determined by GPC using standard polystyrenes.

c Initiation efficiency determined by $M_{\mathrm{k}} / M_{\mathrm{n}}$.

d Calcium hydride and a polystyrene particle having a benzophenone sodium complex. 
Table. 4 Anionic living polymerization of PSM macromonomers.

\begin{tabular}{|c|c|c|c|c|c|c|c|}
\hline \multirow[t]{2}{*}{ Poly $(\mathrm{PSM})_{\mathrm{n}}$} & \multicolumn{2}{|l|}{ PSM } & \multicolumn{2}{|c|}{ Purification } & \multirow{2}{*}{$\begin{array}{l}10^{5} \mathrm{I} \\
\mathrm{mol}\end{array}$} & \multirow[t]{2}{*}{$10^{-4} M_{\mathrm{k}}$} & \multirow{2}{*}{$\begin{array}{l}\text { Polymerization } \\
\text { Initiator/Solvent/ } \\
\text { Temperature/Time }\end{array}$} \\
\hline & $10^{-3} M_{\mathrm{n}}$ & g & $\begin{array}{l}\text { Purging } \\
\text { Time / } \\
\text { h }\end{array}$ & $\begin{array}{l}\text { Solvent/ } \\
\mathrm{ml}\end{array}$ & & & \\
\hline Poly(PSM4)/Bz & $4.6_{2}$ & $0.99_{0}$ & 12 & $\begin{array}{l}\mathrm{Bz} / \\
50\end{array}$ & $2.0_{4}$ & $4.8_{5}$ & $\begin{array}{l}s \text {-BuLi/Bz/ } \\
\text { Room Temp/0.7h - } \\
\text { 134h }\end{array}$ \\
\hline Poly(PSM4), $/ \mathrm{THF}$ & $4.6_{2}$ & $0.99_{6}$ & 12 & $\begin{array}{l}\text { THF/ } \\
55\end{array}$ & $2.4_{2}$ & $4.1_{1}$ & $\begin{array}{l}n-\mathrm{BuLi} / \mathrm{THF} / \\
-78^{\circ} \mathrm{C} / 1.5 \mathrm{~h}-21 \mathrm{~h}\end{array}$ \\
\hline Poly(PSM7)n $/ \mathrm{Bz}$ & $7.1_{0}$ & $0.86_{9}$ & 3 & $\begin{array}{l}\mathrm{Bz} / \\
50\end{array}$ & $0.64_{9}$ & 13.4 & $\begin{array}{l}s \text {-BuLi/Bz/ } \\
\text { Room Temp/7.6h - } \\
68 \mathrm{~h}\end{array}$ \\
\hline
\end{tabular}


Table. 5 Molecular characteristics of the poly(PSM4) ${ }_{10.1}$ star polymer.

\begin{tabular}{|l|l|l|l|l|l|l|l|l|}
\hline Poly(PSM) & \multicolumn{2}{|l|}{$10^{-4} M_{\mathrm{n}}$} & \multicolumn{2}{l|}{$10^{-4} M_{\mathrm{w}}$} & \multicolumn{2}{l|}{$M_{\mathrm{w}} / M_{\mathrm{n}}$} \\
\hline & GPC $^{\mathrm{a}}$ & LALLS $^{\mathrm{b}}$ & OSM $^{\mathrm{c}}$ & GPC $^{\mathrm{a}}$ & LALLS $^{\mathrm{b}}$ & LS $^{\mathrm{d}}$ & LALLS $^{\mathrm{b}}$ & OSM/LS \\
\hline Poly(PSM4) $)_{10.1} /$ THF & $3.2_{4}$ & $4.6_{5}$ & $4.6_{1}$ & $3.5_{0}$ & $4.9_{5}$ & $5.0_{4}$ & $1.0_{6}$ & $1.0_{9}$ \\
\hline
\end{tabular}

a Determined by GPC using standard polystyrenes $\left(M_{\mathrm{n}}{ }^{\mathrm{GPC}}\right.$ and $\left.M_{\mathrm{w}}{ }^{\mathrm{GPC}}\right)$.

b Determined by GPC-LALLS using a special analysis $\left(M_{\mathrm{n}}^{\text {LALLS }}\right.$ and $\left.M_{\mathrm{w}}^{\text {LALLS }}\right)$.

c Determined by membrane osmometry $\left(M_{\mathrm{n}}^{\mathrm{OSM}}\right)$.

d Determined by static light-scattering $\left(M_{\mathrm{w}}{ }^{\mathrm{LS}}\right)$. 


\section{Figure captions}

Figure 1 Reaction time dependence of the metallation efficiency for PPB with sodium mirror.

Figure 2 A glass reactor for purification of St using PPBNa. The symbols of (a) - (e) are explained in the text.

Figure 3 GPC chromatograms of PSM4 and poly(PSM4) star polymers prepared by $s$-BuLi in $\mathrm{Bz}$ at room temperature.

Figure 4 Relationships between $M_{\mathrm{n}}$ and polymer yield, and between $M_{\mathrm{w}} / M_{\mathrm{n}}$ and polymer yield for the anionic living polymerization of the PSM macromonomers.

Figure 5 Relationships between initiation efficiency $\left(f_{\mathrm{I}}\right)$ and polymer yield for the anionic living polymerization of the PSM macromonomers. The purging time is also described in the figure.

Figure 6 Plots of $\pi / c$ against $c$ for poly(PSM4) $)_{10.1}$ prepared by $s$-BuLi in THF at $-78^{\circ} \mathrm{C}$. The membrane osmometry was carried out in toluene at $30^{\circ} \mathrm{C}$.

Figure 7 Zimm plot of poly(PSM4) ${ }_{10.1}$ prepared by $s$-BuLi in THF at $-78^{\circ} \mathrm{C}$, showing the double extrapolation technique. The light-scattering was carried out in benzene at $30^{\circ} \mathrm{C}$.

Figure 8 Plots of $v_{\mathrm{s}}^{\text {star }}$ against the number of arms $(n)$ for the poly(PSM $)_{\mathrm{n}}$ star polymers. The observed $v_{\mathrm{s}}^{\text {star }}$ values of linear PHIC, PSt and PMMA are indicated at a right sides of the vertical axis. The calculated $g_{\text {star }}$ curve of a regular star polymer is also plotted in the figure. 


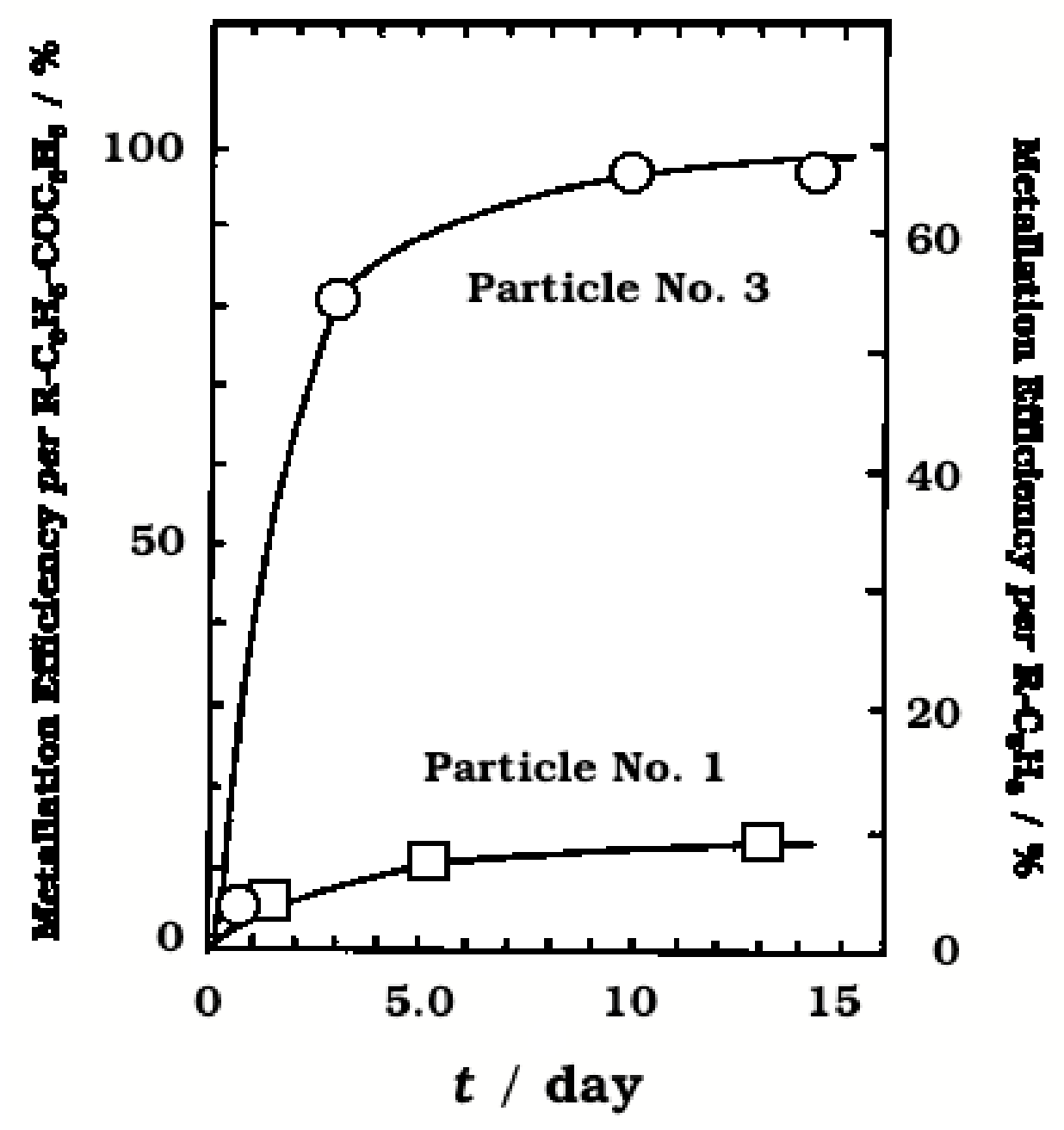

Figure 1 Reaction time dependence of the metallation efficiency for PPB with sodium mirror. 


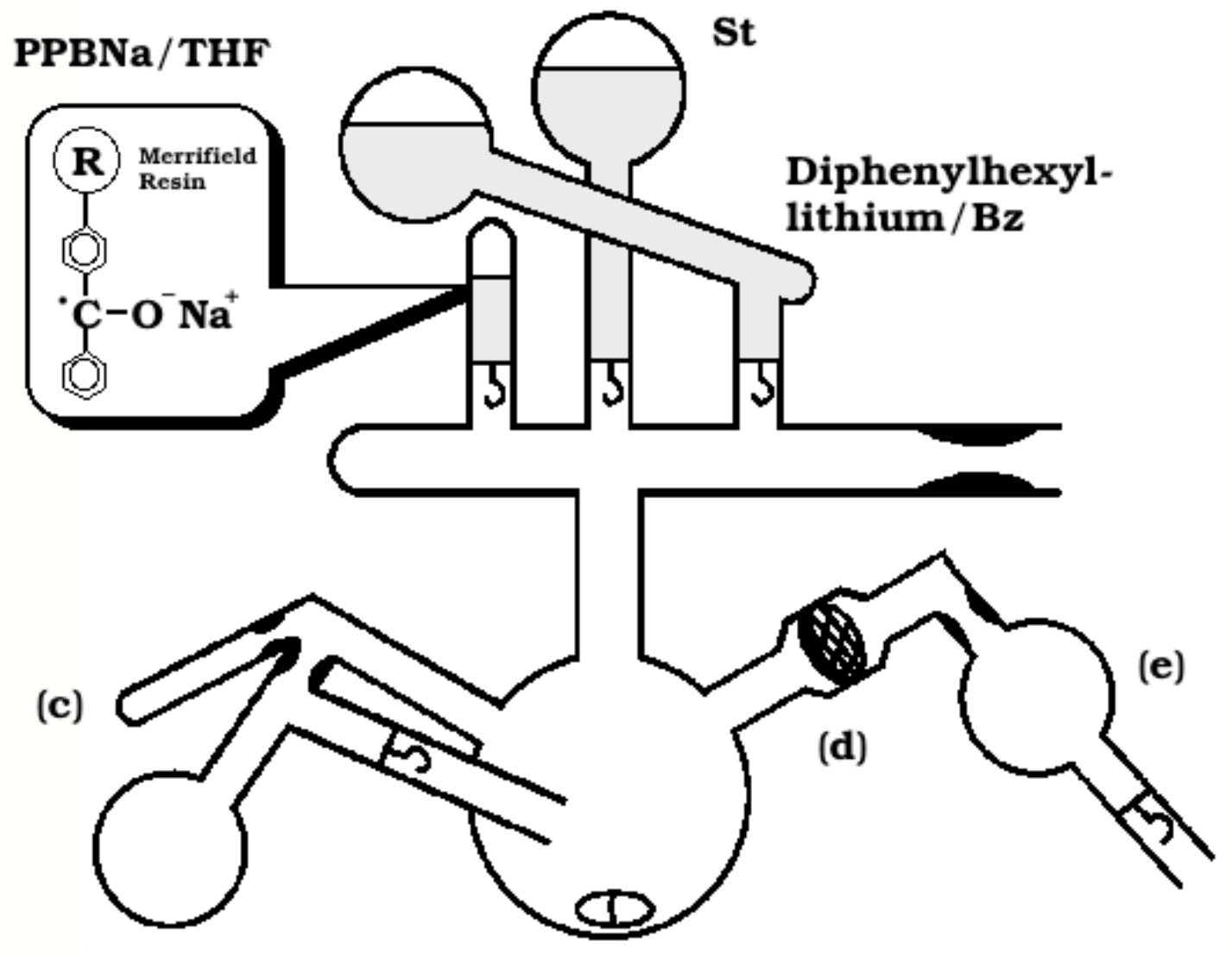

(a)

(b)

Figure 2 A glass reactor for purification of St using PPBNa. The symbols of (a) (e) are explained in the text. 


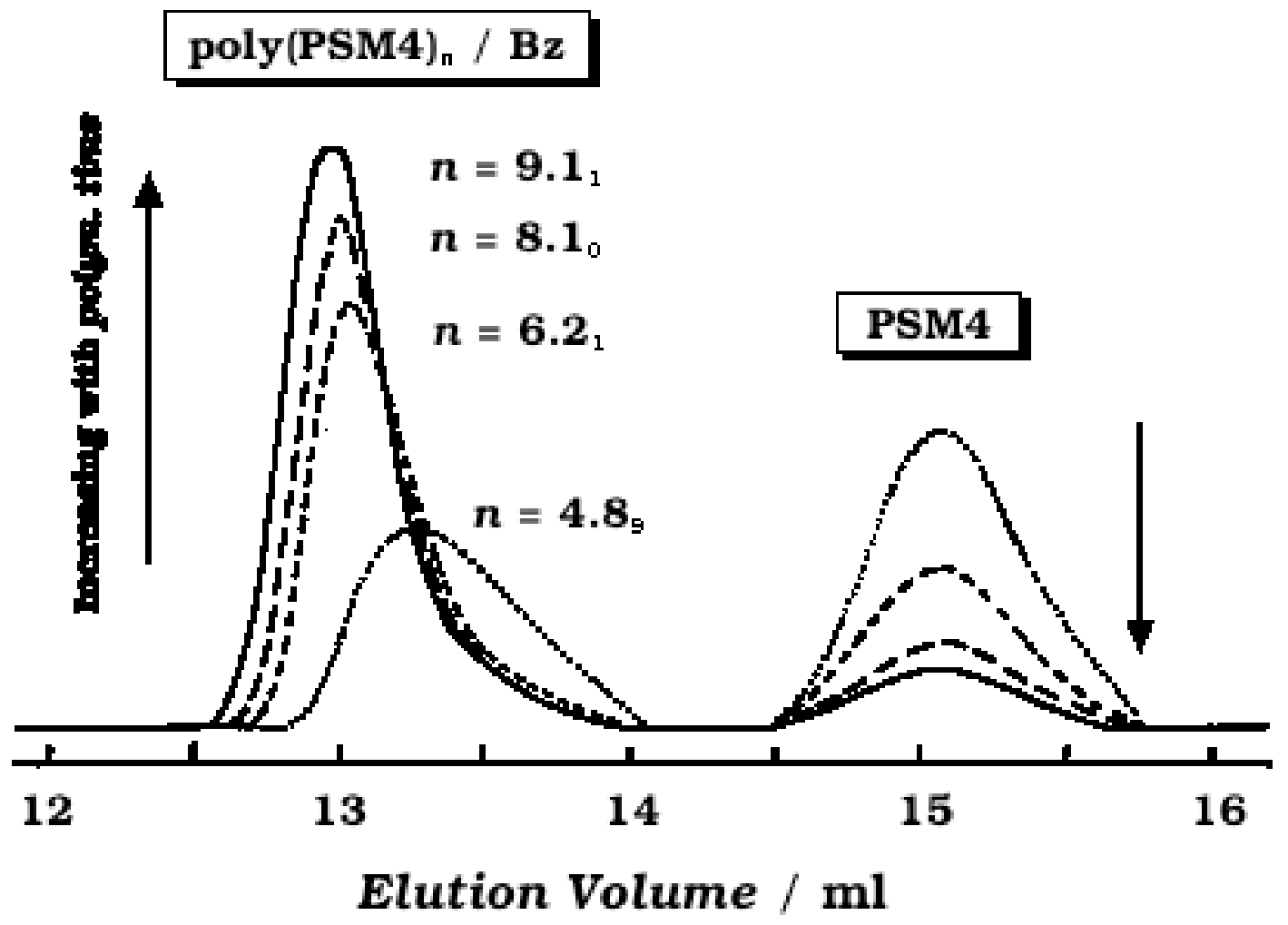

Figure 3 GPC chromatograms of PSM4 and poly(PSM4) $)_{n}$ star polymers prepared by $s$-BuLi in Bz at room temperature. 

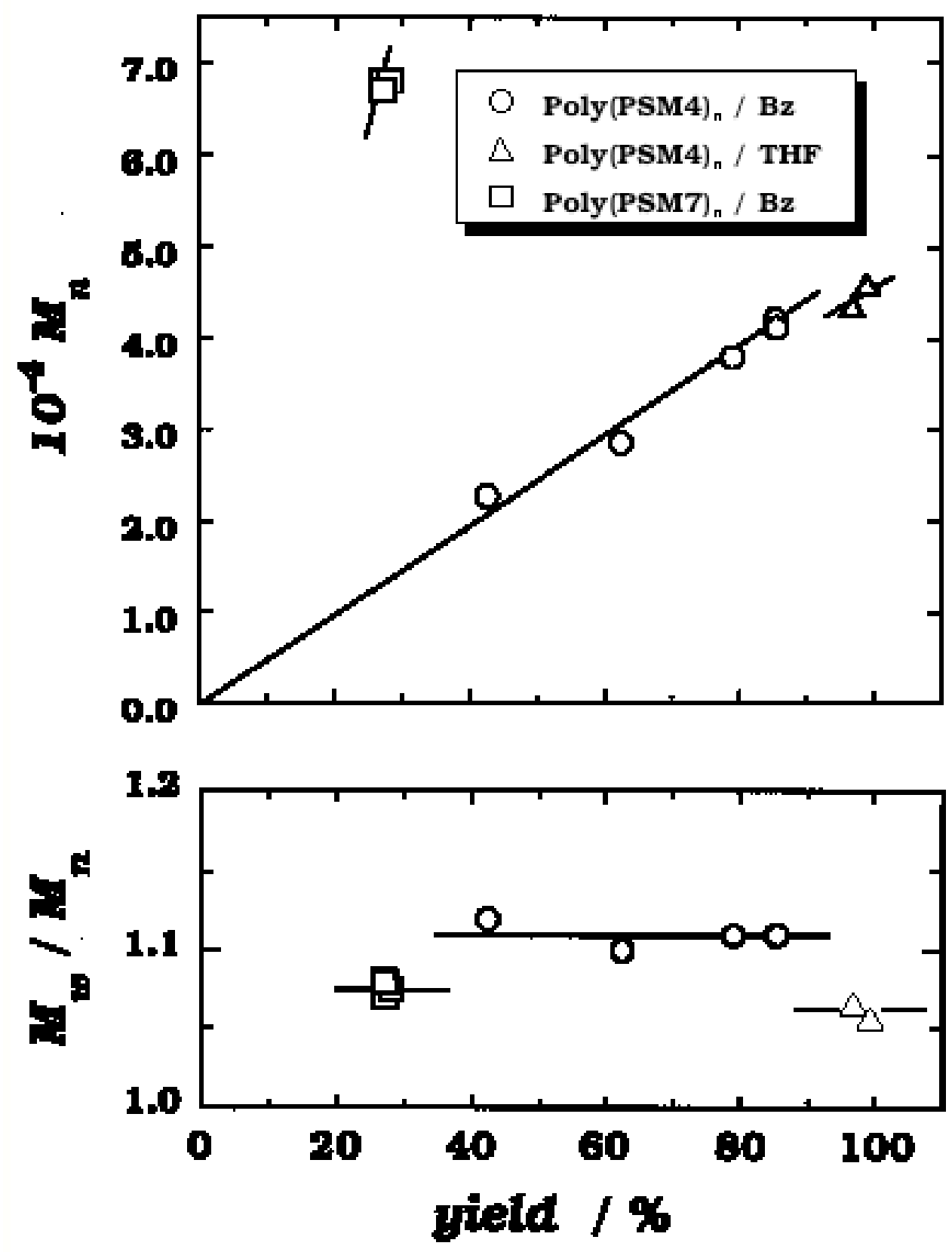

Figure 4 Relationships between $M_{\mathrm{n}}$ and polymer yield, and between $M_{\mathrm{w}} / M_{\mathrm{n}}$ and polymer yield for the anionic living polymerization of the PSM macromonomers. 


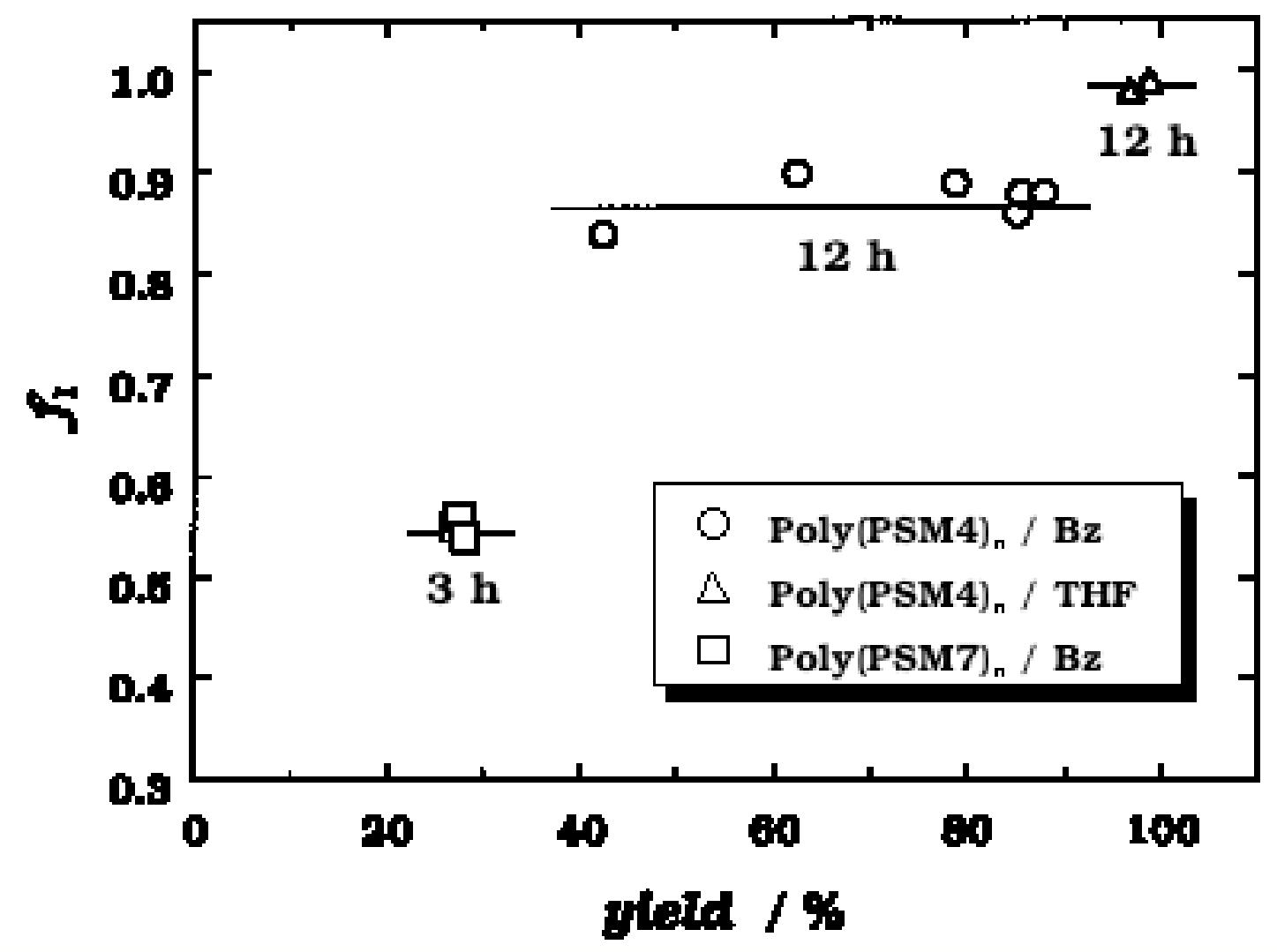

Figure 5 Relationships between initiation efficiency $\left(f_{\mathrm{I}}\right)$ and polymer yield for the anionic living polymerization of the PSM macromonomers. The purging time is also described in the figure. 


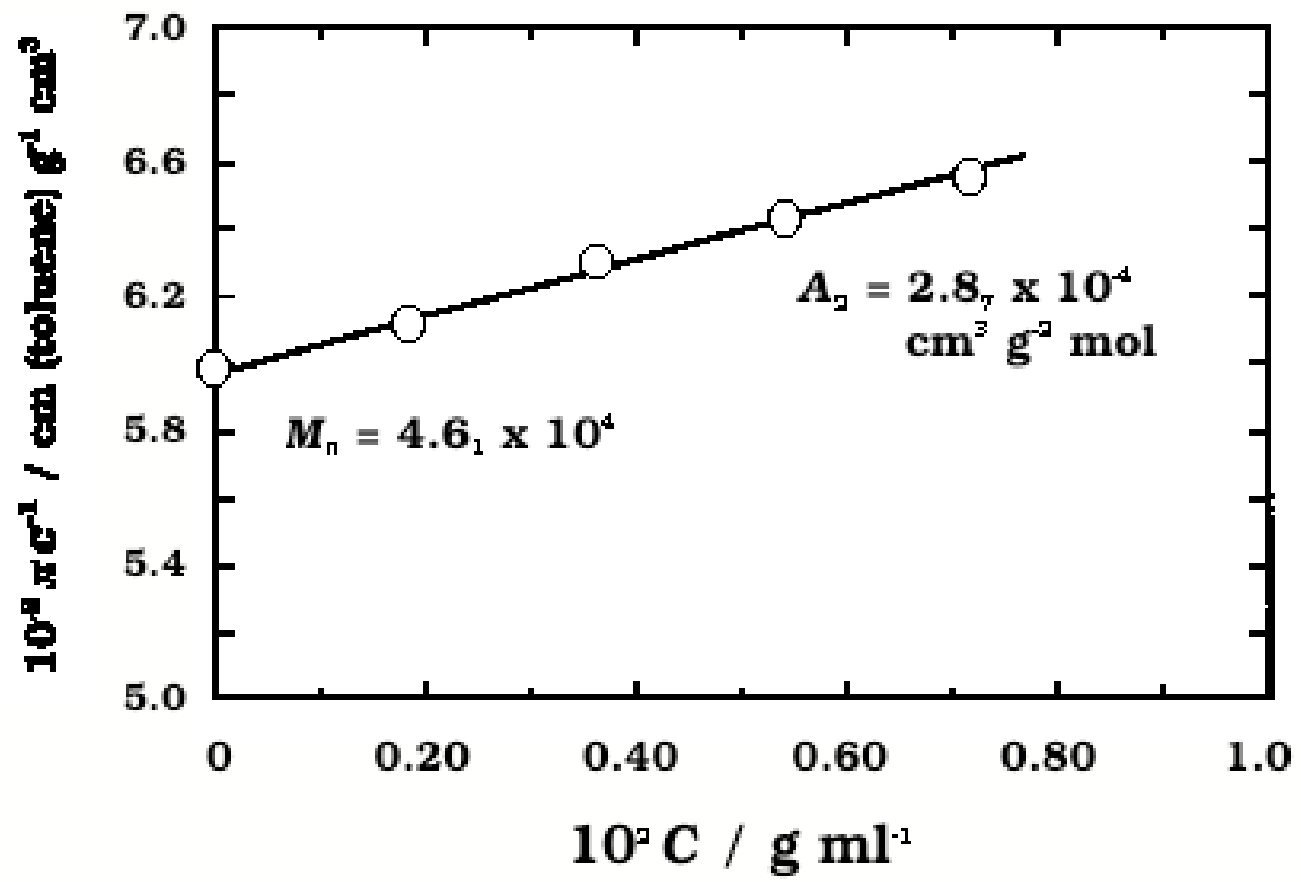

Figure 6 Plots of $\pi / c$ against $c$ for poly(PSM4) $)_{10.1}$ prepared by $s$-BuLi in THF at $-78^{\circ} \mathrm{C}$. The membrane osmometry was carried out in toluene at $30^{\circ} \mathrm{C}$. 


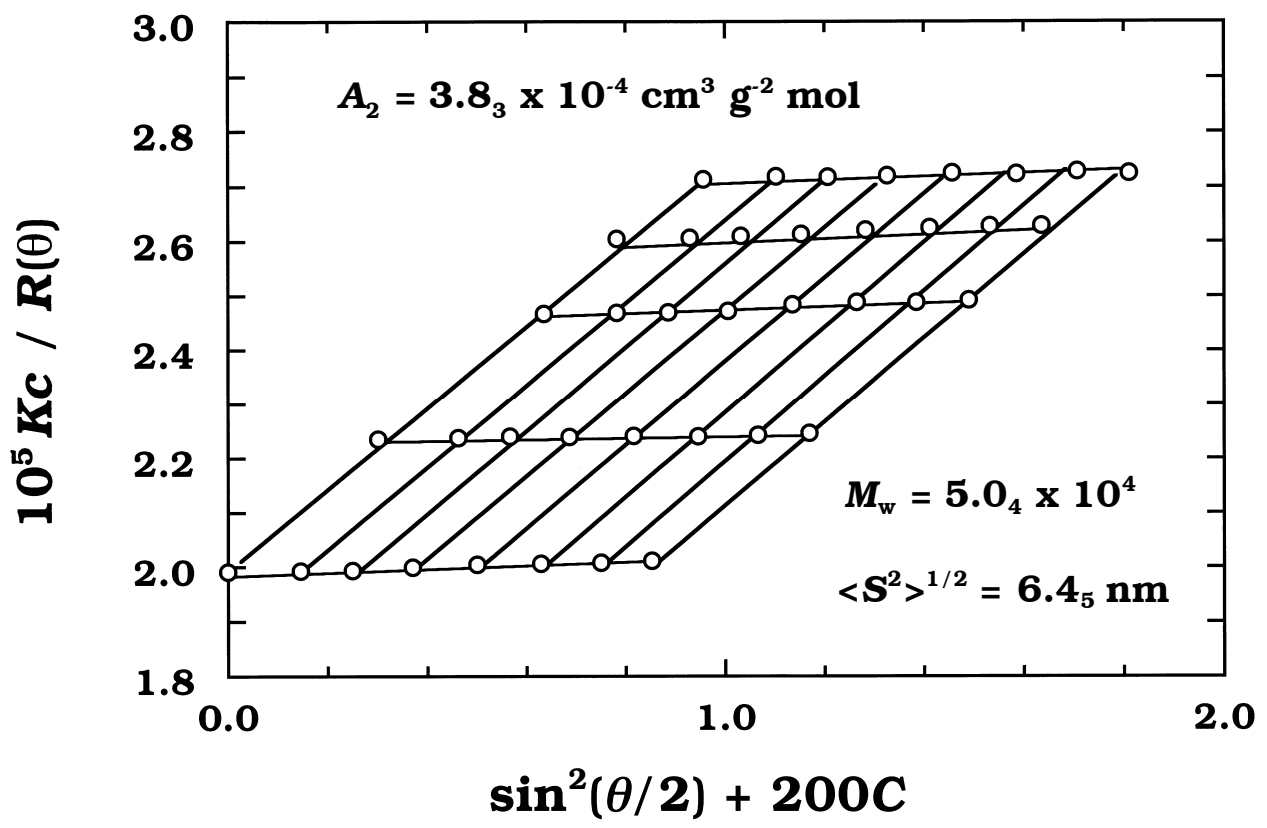

Figure 7 Zimm plot of poly(PSM4) $)_{10.1}$ prepared by $s$-BuLi in THF at $-78^{\circ} \mathrm{C}$, showing the double extrapolation technique. The light-scattering was carried out in benzene at $30^{\circ} \mathrm{C}$. 


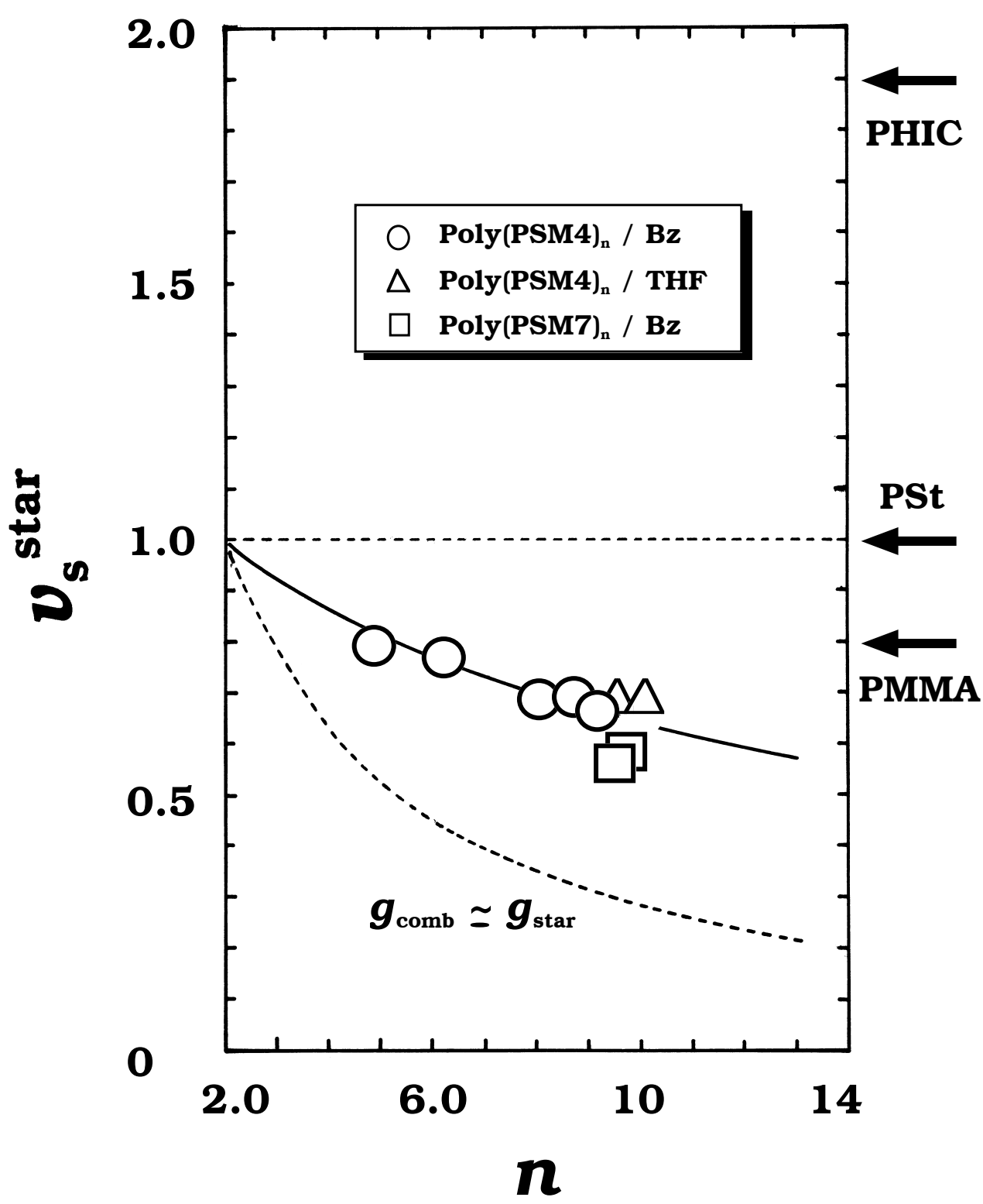

Figure 8 Plots of $v_{\mathrm{s}}^{\text {star }}$ against the number of arms $(n)$ for the poly(PSM) star polymers. The observed $v_{\mathrm{s}}^{\text {star }}$ values of linear PHIC, PSt and PMMA are indicated at a right sides of the vertical axis. The calculated $g_{\text {star }}$ curve of a regular star polymer is also plotted in the figure. 